\title{
Perceived Organizational Politics, Leadership Style and Resilience: How Do They Relate to OCB, If at All?
}

\author{
Aharon Tziner ${ }^{1,2}$, Amos Drory ${ }^{1}$, \& Nir Shilan ${ }^{2}$ \\ ${ }^{1}$ Peres Academic College, Israel \\ ${ }^{2}$ Netanya Academic College, Israel \\ Correspondence: Aharon Tziner, Peres Academic College \& Netanya Academic College, Israel.
}

Received: November 30, 2020

Accepted: December 25, 2020

Online Published: January 8, 2021

doi:10.5539/ibr.v14n2p1

URL: https://doi.org/10.5539/ibr.v14n2p1

\begin{abstract}
The present study examines the relationship between Perceived Organizational Politics (POP) and self-reported Organizational Citizenship Behavior (OCB) focusing on three mediating variables, transactional leadership, transformational leadership, and resilience. 210 employees from a variety of organizations and backgrounds completed a questionnaire containing standard measures of the study variables. Analysis of the data using Amos statistical package shows that OCB is significantly associated with POP, and that leadership styles and resilience significantly mediate this association. The results are discussed in terms of employees' motivation to react to lack of perceived clarity, justice and fairness by enhancing their self-report of OCB engagement. Further research is needed to better understand the meaning of self-reported OCB.
\end{abstract}

Keywords: organizational politics, resilience, organizational citizenship behavior

\section{Introduction}

Although the theme of organizational politics has been amply explored, relatively insufficient attention has been devoted to its likely obnoxious outcomes. This state of affairs is particularly worrisome, considering the undesirable consequences that political wrangling in the workplace might have on employees' proactive organizational behavior, generally labeled as Organizational Citizenship Behavior (OCB).

Organizational politics can be construed from the negative, subjective view of the observer as perceived organizational politics (POP), whereby employees, for example, tend to believe that organizational decision-making processes are fueled by self-serving activities (Vigoda-Gadot \& Drory, 2016). The detrimental effect of such perceived managerial behavior on OCB is possibly mitigated by several factors that should be more thoroughly investigated: We need an in-depth understanding of how, for instance, factors such as managers' leadership styles (transformational vs. transactional, embedded in the organizational setting), and employees' resilience (on the individual level), link to perceived organizational politics on organizational citizenship. We might also wish to capitalize on the job demands-resources (JD-R) theoretical model by positing that harmful work conditions hinder the display of employees' positive, beneficial work behaviors, and that this reticence can be attenuated by enhancing resources (Bakker \& Demerouti, 2007).

In the current study, we postulate that both leadership style and employee resilience may mediate the effect of POP on OCB. Where the styles are appropriate, both transformational and transactional leadership modes can foster personal development and reinforce goal attainment with proportionate rewards. Individual resilience encompasses the competence to bounce back from setbacks and, subsequently, reach higher levels of achievement. These two factors - leadership style and resilience - can act as resources contributing to the attenuation of the low levels of OCB attributable to high levels of POP. We proceed now with further discussion of the aforenoted variables of the current study.

\subsection{Organizational Politics}

Organizational politics (OP) has been attracting considerable academic attention for over four decades (Bergeron \& Thompson, 2020; Hochwarter, Rose \& Jordan, 2020). The term as defined by Ferris, Russ and Fandt (1989) comprises behaviors strategically targeted to maximize self-interests, and likely to undermine collective organizational goals and the interests of other employees in the workplace. Kipnis, Schmidt and Wilkinson (1980) suggested that OP is construed as carrying a negative load of manipulation, subversion, and illegitimate ways of 
attaining egocentric objectives.

Numerous studies have attempted to examine the definition, dynamics, causes and antecedents of this phenomenon and to discuss the implications for organizations' functioning and for employees' well-being. The majority of researchers pointed at the negative sides of OP, associating it with a climate of manipulations, lack of justice and fairness, and self-serving motives. Other researchers noted some positive aspects of OP, as well associating it with effective leadership and constructive coalition building (Bacharach, 2005). Many of the studies focused on the negative effects of OP in employees. Within political environments, employees tend to feel threatened by the uncertainty, ambiguity and the self-interest actions that occur with individuals (Harris, Harris \& Wheeler, 2009). Others proposed that organizational politics were the source of conflict and stress at the workplace (Ladebo, 2006; Vigoda-Gadot \& Kapun, 2005). Other studies highlighted the negative effect of OP on job outcomes and job performance (e.g., Drory, 1993; Ferris \& Kacmar, 1992; Kacmar, Bozeman, Carlson, \& Anthony, 1999; Vigoda-Gadot, 2003). Vigoda-Gadot and Drory (2016) recorded that empirical research has substantiated both descriptions of organizational politics and the harmful effects that such politics have on employees. It was further found that trust and social support can moderate the negative effect of OP on job outcomes (Vigoda-Gadot \& Talmud, 2010). Surprisingly, one aspect that has not yet been widely explored is the potential coping mechanisms, which employees may adopt in an attempt to reduce the adverse effect of OP. We shall attempt to address this aspect at a later point.

\subsection{Organizational Citizenship Behavior}

Organ (1988) identified a set of work-related behaviors described as "individual behavior that is discretionary, not directly or explicitly recognized by the formal reward system, and that in the aggregate promotes the effective functioning of the organization".

These activities, which are neither formally recognized nor rewarded, have been subsumed under the heading of Organizational Citizenship Behavior (OCB) (Chernyak-Hai \& Rabenu, 2018). Notably, in the increasingly dynamic and competitive organizational environment, OCB is considered a highly-valued contributor to the effective functioning of an organization. In recent years, there has been increasing interest in OCB recorded by many management scholars (e.g., Bogler \& Somech, 2019; Henderson, Foster, Mathews, \& Zicker, 2020; Oren et al., 2013; Parker, Subrahmanian, \& Hussain, in press; Turnipseed, 2018). According to Tziner and Sharoni (2014), since the year 2000, no fewer than four hundred articles on OCB and related constructs have been published by organizational researchers.

Past studies of OCB indicate the utility of differentiating between OCB targeted at the organization (OCB-O) and OCB directed towards individuals at the workplace (OCB-I) (Podsakoff et al., 2009; Spitzmuller, Van Dyne, \& Ilies, 2008). This distinction has been employed in this investigation to explore whether, concerning each specific category of OCB, differential patterns of relationships with the other variables unfold.

While OCB was initially considered a highly desirable phenomenon, reflecting a spirit of voluntarism and goodwill towards the organization and coworkers, Bolino (1999) was the first to suggest that OCB may often be motivated by impression management motives. Employees may enhance their OCB and the awareness of their environment to their OCB in order to further their own selfish agenda. Bolino goes further to suggest that when organizational processes such as rule enforcement, performance appraisal, and advancement decisions become politicized and subjective, rather than objective, an individual's image tends to become important. Ralston and Elsass (1989) suggested that individuals used impression management strategies in reaction to political environments in an attempt to improve their personal image, using acts of citizenship to achieve it. We therefore hypothesize that:

H1: OCB will be positively related to the perception of OP.

However, in an attempt to shed further light on the mechanism through which organizational politics relate positively to $\mathrm{OCB}$, we elected to examine transformational and transactional leadership styles, as well as resilience, as possible significant mediating variables - constructs that we considered to have reasonable explanatory potential.

\subsection{Transformational and Transactional Leadership Styles}

Leadership styles, of course, vary among leaders. Of particular note, recent literature on the subject has distinguished between two specific styles of leadership labeled, respectively, transformational and transactional leadership. (Kanat-Maimon, Elimelech, \& Roth, 2020; Shkoler \& Tziner, 2020).

Transformational leaders tend to inspire subordinates (or followers) and entire collectives. Transformational leadership operates through mechanisms of affect, cognitions, and behaviors, and such leaders influence and 
manage their followers' actions via shared belief systems (cognitions), positive emotions (affect), and through the mutual expression of a collective vision (Bass, 2007; Jung \& Avolio, 1999; Kark, Van Dijk, \& Vashdi, 2018; Perilla-Toro \& Gómez-Ortiz, 2017; Xenikou, 2017; Yaffe \& Kark, 2011). The transformational leadership paradigm is essentially a two-dimensional framework (Hernandez, Eberly, Avolio, \& Johnson, 2011). Although commands filter down the hierarchy, the leader is open to debate, and may also be influenced by the followers, so that there is a reciprocal dyadic process rather than a unidirectional leadership pattern.

In contradistinction, transactional leadership designates the 'traditional' leader. The leadership mechanism originates from the leader, and the leader alone. Commands go down the hierarchy and are unidirectional or even unilateral. The leader will more likely invoke an authoritative structure directed at influencing followers' behaviors. This style has been conceptualized in terms of an exchange process, in which rewards are offered for compliance, and punishment for non-compliance (Bass, 2007; Jung \& Avolio, 1999; Yaffe \& Kark, 2011). The transactional leader sets standards and norms and highlights obligations, while directing subordinates to perform tasks in the "correct and expected way", which encourages conformism and submission (Bass, 1985; Gorman et al., 2012; Kark, Katz-Navon, \& Delegach, 2015; Kark, Van Dijk, \& Vashdi, 2018).

We propose that employees' perception of the leadership styles described above will mediate the relationships between OP and OCB. We maintain that the perception of both leadership styles impacts the employees' trust in reward allocation consistency, transparency and justice. Hence:

H2: The more employees feel that they can rely on their superiors to ensure fair and just allocation of rewards, the less they would react to higher OP by increasing their citizenship behavior.

\subsection{Resilience}

While resilience may be considered an "experience" (Madrid, Diaz, Leka, Leiva, \& Barros, 2018, p. 465), the term is usually defined as "the human ability to adapt in the face of tragedy, trauma, adversity, hardship, and ongoing significant life stressors" (Newman, 2005, p. 227). Notably, in the context of positive adaptation to stressful events and adversity, the concept has been researched extensively in the literature (e.g., American Psychological Association, 2014; Britt, Shenn, Sinclair, Grossman \& Klieger, 2016; Fikretoglu \& McCreary, 2012; Lau, Wilkins-Yel, \& Wong, 2020; Meredith et al., 2011; Oshio, Taku, Hirano, \& Saeed, 2018).

Highly resilient individuals have emotional stability (Masten, 2001), and their emotions seem to be more positive than negative. Following Bonnano (2004), resilience reflects the ability to maintain a stable equilibrium in the wake of stressful events. For Carver (1998), resilience refers to (a) people's ability to return to their previous levels of functioning; (b) as indicated above, the competence to bounce back from setbacks; and (c) subsequently, to reach higher levels of achievement (Crawford, LePine \& Rich, 2010; Walpita \& Arambepola, 2020). In sum, following Hobfoll (2011), resilience refers to people's ability to endure the most detrimental effects of stressful challenges, and still remain vital, steadfast, and engaged in important life tasks. We hence propose that:

H3: Employee resilience will mediate the relationship between OP and OCB. The higher the resilience, the stronger the inclination to react to OP by positive and constructive out-of-role behaviors in an attempt to maximize the chance of higher reward allocation in an uncertain environment.

To sum up, we hypothesize that these variables interrelate as displayed in the theoretical model in Figure 1; namely, that the variables of leadership style and resilience mediate the relationship between organizational politics $(\mathrm{OP})$ and $\mathrm{OCB}$.

According to this model, organizational politics will be positively related to OCB. We hypothesize that the more the climate is perceived as lacking fair and systematic practices of reward allocation and justice, the greater the employee's inclination to create a positive image by various means such as out-of-role citizenship behavior in the hope of increasing the probability of maximizing rewards.

Mediating variables: The model further suggests that the relations between OP and OCB will be mediated by transactional leadership, transformational leadership and personal resilience. The rationale behind the choice of these mediating variables is as follows.

Transactional leadership - We suggest that when operating in a political climate, employees look around for support systems, which may counterbalance the psychological uncertainty and relieve potential anxiety. Naturally, they look up to their immediate superior for supporting clues. The transactional leader offers clarity and stability regarding the rules of exchange in terms of what work inputs will be rewarded and what the rewards will be. This style may lower the uncertainty caused by the political climate, and may reduce the need to resort to out-of-role activities such as OCB in the hope of creating a positive image, which will hopefully increase the probability of positive reward. 
Transformational leadership - in contrast to the transactional leader, the transformational leader attempts to inspire and to instill values rather than offer rewards in exchange for work input. This approach does not alleviate the feeling of insecurity and mistrust caused by political climate. It is therefore hypothesized that when the climate is already perceived as political, the less the employee can rely on the superior to ensure clarity and fair exchange, the greater the effort to resort to OCB will be.

Resilience - We suggest that highly resilient individuals have a strong capability for dealing with unfavorable situations. They are self-assured and ready to fight to overcome obstacles. They utilize their resources expediently and in a positive fashion, thus improving their standing with their superiors in a relatively unpredictable situation, and increasing the probability of being positively rewarded. When they face a highly political climate, appearing to lack fairness in the allocation of rewards, they are expected to diversify their efforts to include more $\mathrm{OCB}$, and report on doing so more strongly.

The goal of the study reported in this paper was to ascertain to what extent this theoretical model holds up.

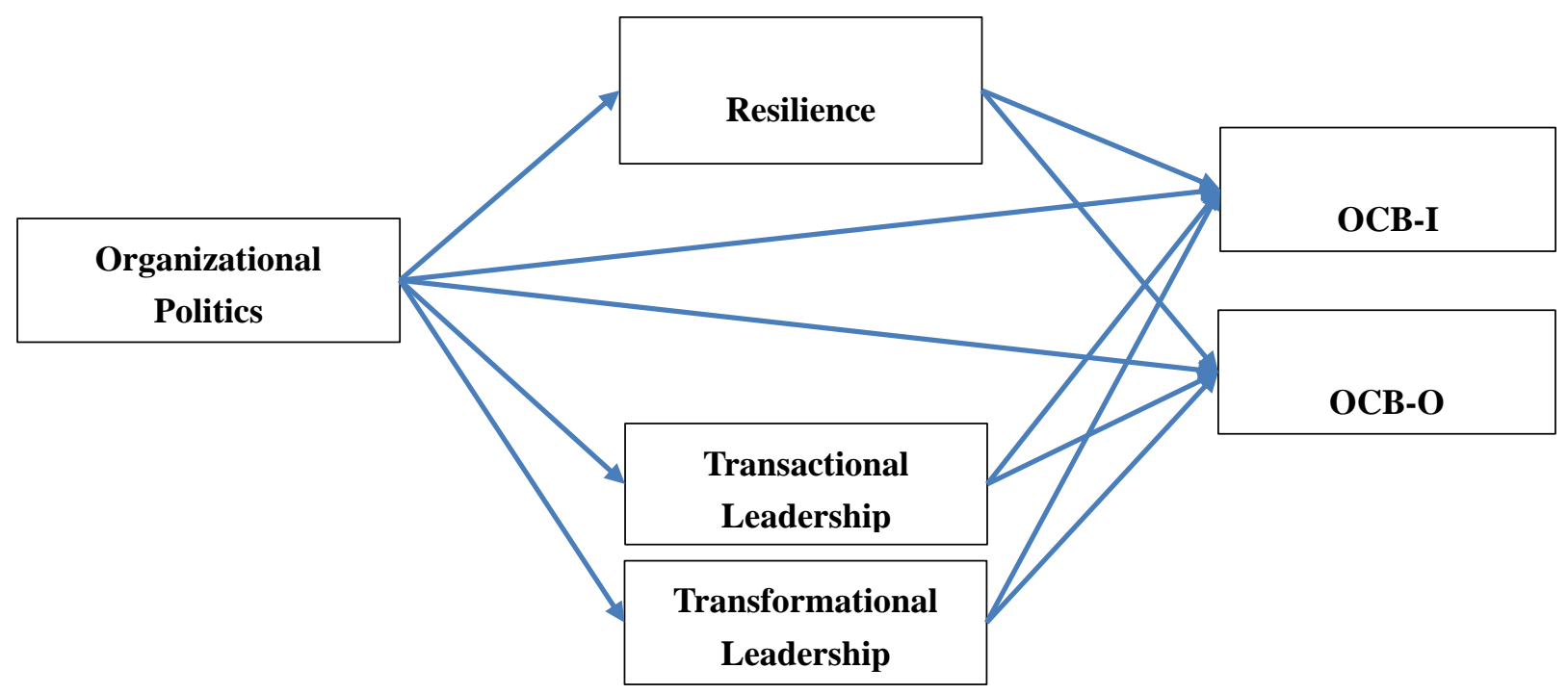

Figure 1. Research Model - The Mediated Association between Organizational Politics and OCB

Note. $O C B-I=$ interpersonal dimension of organizational citizenship behaviors. $O C B-O=$ organizational dimension of organizational citizenship behaviors

\section{Method}

\subsection{Participants}

The sample consisted of 210 employees, of which $53.3 \%$ were men and $46.7 \%$ women between the ages $20-67$ $(M=41.68, S D=9.93)$; married $(68.1 \%)$, single $(13.3 \%)$, divorced or separated $(15.2 \%)$, and widowed $(3.3 \%)$. In terms of education, $29.5 \%$ had completed a high-school education, $44.3 \%$ held a BA, and $26.2 \%$ an MA and above. By religiosity, 5.7\% were orthodox (or very religious), $27.1 \%$ religious, $34.3 \%$ traditional/ conservative, $29 \%$ secular, and 3.8\% atheists. In addition, regarding job tenure, $0-5$ years: $21 \%$, 6-10 years: $22.9 \%$, 11-15 years: $28.1 \%, 16-20$ years: $14.3 \%$, and 20 years and above: $13.8 \% .41 .9 \%$ worked in the public sector, $34.3 \%$ in the private sector, $14.8 \%$ in high-tech industries, and only $9 \%$ were self-employed/freelancers. Overall, $56.2 \%$ held a non-managerial role, while $43.8 \%$ held some kind of managerial role within the organization.

The questionnaires were administered by the third author under the supervision of the first one. Participation in the survey was voluntary. Anonymity and discretion of the participants and the derived data were guaranteed, and included an informed consent statement at the beginning of the survey, ascertaining their agreement to participate. The information was treated responsibly, according to legislation in the field of data confidentiality. No incentives were offered to the participants for their cooperation. The participants were assured of our respect for data confidentiality throughout the stages of collection, processing, storage, dissemination, and archiving. No personal data of the respondents was recorded, making them impossible to identify. In a way, they could be regarded as convenience subjects. 


\subsection{Measures}

Leadership styles were measured using the 36-item Multifactor Leadership Questionnaire (MLQ; Avolio \& Bass, 1991), on a Likert-type scale ranging from 1 ("strongly disagree") to 6 ("strongly agree"). Transactional leadership was assessed by 12 items; for example, "Your leader assists you based on effort." In the present study, reliability was good $(\alpha=.81, M=3.62, S D=0.59)$. Transformational leadership was gauged by 24 items; for example, "Your leader teaches and coaches." In the present study, reliability was high $(\alpha=.93, M=3.73, S D=$ $0.80)$.

Organizational citizenship behaviors were gauged by a 14-item measure rated on a Likert scale ranging from 1 ("strongly disagree") to 6 ("strongly agree") to assess employees' organizational behaviors (Williams \& Anderson, 1991). OCB-I (interpersonal) is indicated by items 1-7, for example: "Helps others who have heavy workloads." In the present study, reliability was good $(\alpha=.85, M=4.07, S D=0.86$ ). OCB-O (organizational) is indicated by items 8-14 (items 10-12 are reverse-coded), for example: "Adheres to informal rules devised to maintain order." In the present study, reliability was adequate $(\alpha=.70, M=3.84, S D=0.72)$.

Resilience was measured using the 25-item Connor-Davidson Resilience Scale (CD-RISC; Connor \& Davidson, 2003), on a Likert-type scale ranging from 1 ("rarely true") to 6 ("true nearly all of the time"). For example, "When things look hopeless, I don't give up" and "Able to adapt to change." In the present study, reliability was high $(\alpha=.96, M=3.98, S D=0.83)$.

Control variables. In further analyses, we also controlled for the effects of gender, age, tenure, managerial role, sector/industry, religiosity, and education.

Organizational politics was gauged using the 12-item Perceptions of Politics Scale (POPS; Kacmar \& Carlson, 1997), on a Likert-type scale ranging from 1 ("strongly disagree") to 6 ("strongly agree"). For example, "There has always been an influential group in this department that no-one ever crosses." In the present study, reliability was subpar $(\alpha=.51)$. Thus, after employing a factor analysis, six items were discarded from further analyses due to reliability concerns for two main reasons: (1) qualitatively - these items were essentially different from the other six items, and (2) quantitatively - these items did not add any meaningful mathematical information to the latent construct of organizational politics (e.g., Corrected Item-Total Correlations ranged between [-.07]-[.15], which is unacceptable by normal standards) (for further reading, see: Henderson, Foster, Matthews, \& Zickar, 2019). After doing so, the alpha coefficient was adequate $\alpha=.83, M=3.81, S D=0.87$ ).

As shown in Table 1, these analyses produced clean, adequate, and reliable factors that act as references for further analyses in this study from this point onwards.

\section{Results}

Initially, three tests were employed to assess the extent to which inter-correlations among the variables might be an artifact of common method variance (CMV): (a) Harman's single-factor method (a confirmatory factor analysis [CFA] in which all items are concurrently loaded on one single factor); (b) a common latent factor method (a CFA in which all items are loaded on both their expected factors and one common latent factor is loaded on each of the items respectively, but are uncorrelated to their respective latent factors); and (c) a CFA without a common latent factor, as proposed by Podsakoff et al. (2003), and backed by Jawahar, Schreurs and Mohammed (2018) and Tziner, Shkoler and Fein (2020).

The Harman's single-factor method accounted only for $27.60 \%$ of the explained variance: ${ }^{2}(3,519)=$ $12,513.77, \mathrm{p}=.000,{ }^{2} / \mathrm{df}=3.56, \mathrm{CFI}=.63, \mathrm{NFI}=.76, \mathrm{GFI}=.83$, SRMR $=.17$, RMSEA $(90 \% \mathrm{CI})=.27$ (.13-.29), p-close $=.000$. In addition, the common-latent factor accounted only for $24.19 \%$ of the explained variance: ${ }^{2}(3,317)=9,325.17, \mathrm{p}=.000,{ }^{2} / \mathrm{df}=2.81, \mathrm{CFI}=.75, \mathrm{NFI}=.81, \mathrm{GFI}=.84$, SRMR $=.13$, RMSEA $(90 \% \mathrm{CI})=.18(.07-.22), \mathrm{p}$-close $=.000$. Last, the CFA analysis (without a common latent factor) accounted only for $22.95 \%$ of the explained variance: ${ }^{2}(3,107)=6,493.62, \mathrm{p}=.000, \quad 2 / \mathrm{df}=2.09, \mathrm{CFI}=.84, \mathrm{NFI}=.86$, $\mathrm{GFI}=.90, \mathrm{SRMR}=.10$, RMSEA $(90 \% \mathrm{CI})=.12(.00-.16)$, p-close $=.009$. As can be seen, the common latent factor method produced better indices and less CMV. While these results do not completely exclude the likelihood of same-source bias (i.e., CMV), following Podsakoff et al. (2003), less than $50 \%\left(\mathrm{R}^{2}<.50\right)$ of the explained variance accounted for by the first emerging factor-together with the poor model fit for each analysis - indicates that CMV is an unlikely explanation of our investigation's findings. Additionally, it is important to note that prior to conducting further analyses, we followed Tehseen, Ramayah and Sajilan's (2017) suggestion for correcting CMV via construct-level correction. Although not completely devoid of CMV, its level has been reduced to a bare-minimum for each variable.

Furthermore, zero-order Pearson correlations were calculated in order to observe the intercorrelations among the 
research variables, as shown in Table 1 (again, after correcting for CMV, as mentioned before).

Table 1. Pearson Correlations Matrix $(\mathrm{N}=210)$

\begin{tabular}{llccccc}
\hline & & 1 & 2 & 3 & 4 & 5 \\
\hline 1. & Org. Politics & & & & & \\
2. & Resilience & $.56^{* * *}$ & & & & \\
3. & Transformational & $.38^{* * *}$ & $.57^{* * *}$ & & & \\
4. & Transactional & $.51^{* * * *}$ & $.43^{* * *}$ & $.57^{* * *}$ & & \\
5. & OCB-I & $.49^{* * *}$ & $.72^{* * * *}$ & $.48^{* * *}$ & $.32^{* * *}$ & \\
6. & OCB-O & $.14^{*}$ & $.58^{* * *}$ & $.19^{* *}$ & $-.16^{*}$ & $.54^{* * *}$ \\
\hline
\end{tabular}

Notes: $* p<.05, * * p<.01, * * * p<.001$. Org. = organizational. Transformational = transformational leadership style. Transactional $=$ transactional leadership style. OCB-I $=$ interpersonal dimension of organizational citizenship behaviors. OCB-O = organizational dimension of organizational citizenship behaviors

To test the mediation model as a whole, we utilized the AMOS software program (v. 23). The model's fit is adequate. However, to distinguish the model from other factorial alternatives, we tested the same model with some variations to it, as presented in Table 2. As can be seen in Table 2, the fit of the model is at its relative best when testing the current model as originally presented in Figure 1. As such, this is the model the research will continue using. Moreover, further path analysis (with 95\% CI and 5,000 resampling based on bias-corrected bootstrapping) is presented in Tables 3 and 4, and Figure 2.

Table 2. Measurement Model's SEM Analyses and Comparisons

\begin{tabular}{llllllllll}
\hline Model & \multicolumn{1}{c}{$(\mathrm{df})$} & Sig. & \multicolumn{1}{c}{$/ \mathrm{df}$} & CFI & NFI & IFI & GFI & SRMR & RMSEA $^{1}$ \\
\hline Base $^{2}$ & $9.21(1)$ & .002 & 9.21 & .99 & .99 & .98 & .98 & .05 & $.20(.10-.32)$ \\
OCB $^{3}$ & $12.88(1)$ & .000 & 12.88 & .90 & .91 & .88 & .94 & .08 & $.17(.15-.25)$ \\
Leadership $^{4}$ & $8.46(1)$ & .000 & 8.46 & .84 & .87 & .89 & .90 & .05 & $.26(.13-.37)$ \\
\hline
\end{tabular}

Notes. (1) $90 \%$ CI. (2) Base = original model as depicted in Figure 1. (3) OCB variable combined as one variable instead of its two dimensions. (4) Leadership variable combined as one continuous variable instead of two

Table 3. Path analysis for the full research model

\begin{tabular}{|c|c|c|c|c|c|c|}
\hline Path & & & & $E$ & $t$-test & Sig. \\
\hline Org. Politics & $\rightarrow$ & Resilience & .56 & 0.06 & 9.66 & .000 \\
\hline Org. Politics & $\rightarrow$ & Transactional & .51 & 0.04 & 8.48 & .000 \\
\hline Org. Politics & $\rightarrow$ & Transformational & .39 & 0.06 & 6.21 & .000 \\
\hline Org. Politics & $\rightarrow$ & OCB-I & .15 & 0.06 & 2.39 & .017 \\
\hline Org. Politics & $\rightarrow$ & OCB-O & -.07 & 0.05 & -1.21 & .227 \\
\hline Resilience & $\rightarrow$ & OCB-I & .60 & 0.06 & 9.70 & .000 \\
\hline Resilience & $\rightarrow$ & OCB-O & .76 & 0.05 & 12.78 & .000 \\
\hline Transactional & $\rightarrow$ & OCB-I & -.08 & 0.09 & -1.36 & .172 \\
\hline Transactional & $\rightarrow$ & OCB-O & -.46 & 0.07 & -7.93 & .000 \\
\hline Transformational & $\rightarrow$ & OCB-I & .12 & 0.07 & 1.93 & .049 \\
\hline Transformational & $\rightarrow$ & OCB-O & .04 & 0.06 & 0.59 & .556 \\
\hline
\end{tabular}

Notes: $\mathrm{SE}=$ standard error. Org. $=$ organizational. Transformational $=$ transformational leadership style. Transactional $=$ transactional leadership style. OCB-I = interpersonal dimension of organizational citizenship behaviors. OCB-O = organizational dimension of organizational citizenship behaviors

Table 3 depicts the indirect effects analyses via bootstrapping. As can be seen, transformational leadership style, transactional leadership style, and resilience act as mediators between Organizational Politics and OCB-I/OCB-O (an exception is the mediation effect between Organizational Politics and OCB-O which is non-significant ( $p=.182$ and $p=.159$, respectively). 
Table 4. SEM bootstrapping (95\% CI) for the standardized indirect effects

\begin{tabular}{llllllll}
\hline Path & & & & & LL & UL & Sig. \\
\hline Organizational Politics & $\rightarrow$ & Resilience & $\rightarrow$ & OCB-I & 0.26 & 0.47 & .000 \\
Organizational Politics & $\rightarrow$ & Resilience & $\rightarrow$ & OCB-O & 0.28 & 0.53 & .000 \\
\hline Organizational Politics & $\rightarrow$ & Transactional & $\rightarrow$ & OCB-I & -0.27 & -0.06 & .003 \\
Organizational Politics & $\rightarrow$ & Transactional & $\rightarrow$ & OCB-O & -0.02 & 0.15 & .182 \\
\hline Organizational Politics & $\rightarrow$ & Transformational & $\rightarrow$ & OCB-I & 0.05 & 0.27 & .000 \\
Organizational Politics & $\rightarrow$ & Transformational & $\rightarrow$ & OCB-O & -0.02 & 0.21 & .159 \\
\hline
\end{tabular}

OCB-I = interpersonal dimension of organizational citizenship behaviors. OCB-O = organizational dimension of organizational citizenship behaviors; LL = lower limit of CI; UL = upper limit of CI; (1) Mediators = transformational leadership + transactional leadership + resilience

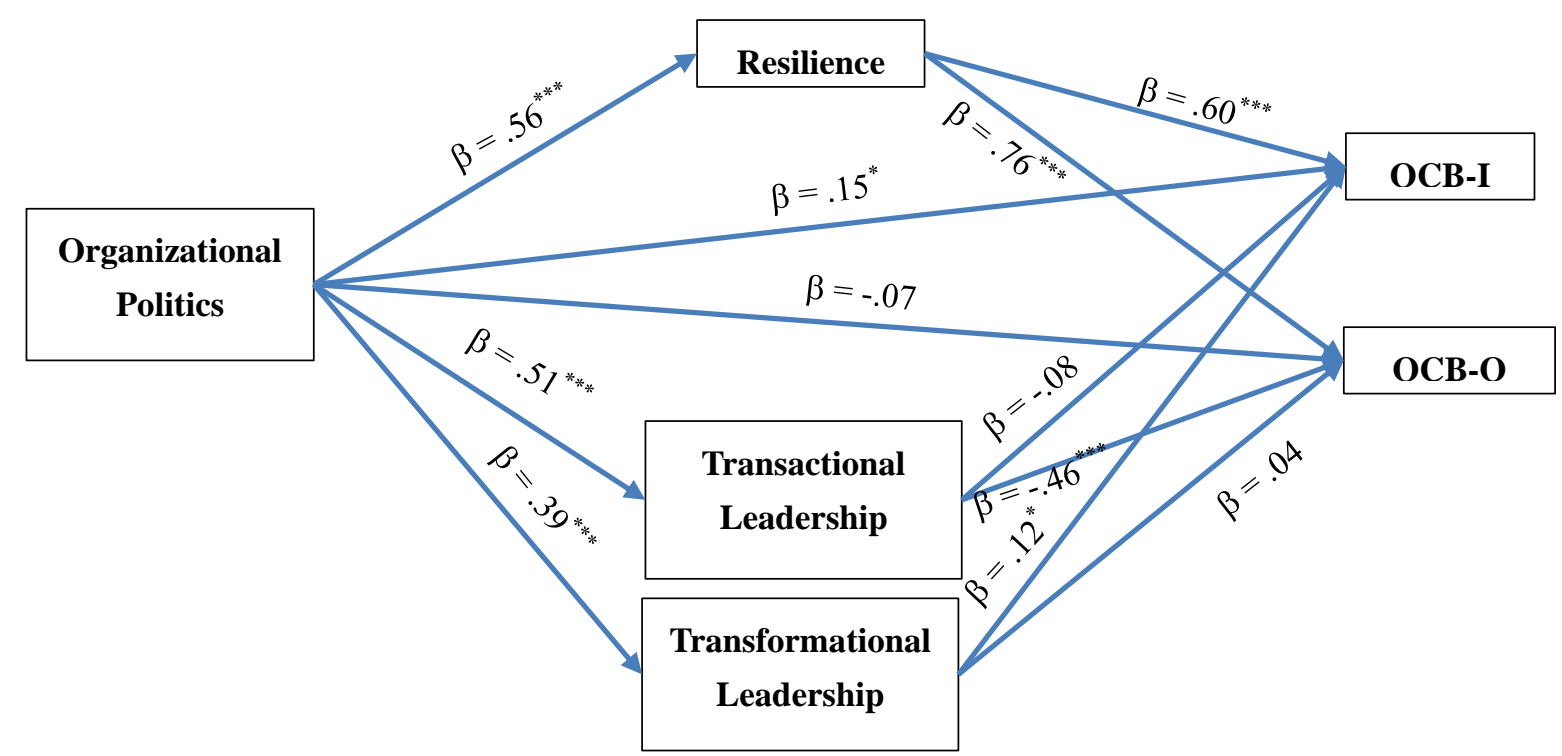

Figure 2. Path Analysis and Standardized Regression Coefficients for the Research Model

Notes: $* \mathrm{p}<.05, * * \mathrm{p}<.01, * * * \mathrm{p}<.001$. OCB-I = interpersonal dimension of organizational citizenship behaviors. OCB-O = organizational dimension of organizational citizenship behaviors

\section{Discussion}

As indicated in the introduction, the first generation of OCB research portrayed this class of work-related behavior as a reflection of benevolent attitudes and a predisposition of the "good soldier". This notion was later challenged by other researchers, who questioned the validity of this assessment (Bolino, Klotz, Turnley, \& Harvey, 2013). Bolino (1999) suggested, for example, that OCB may be impression-enhancing and self-serving. Although, by definition, OCB is not officially rewarded by the organization, there may yet prevail an informal expectation by management that OCB would occur and, consequently, employees would feel compelled to behave as good citizens and to create the impression of engagement in OCB (Porpora, 1989; Vigoda-Gadot, 2006). We, therefore, assume that a self-reported OCB score reflects two components; namely, (a) actual citizenship behavior, and (b) an attempt to establish an impression of OCB.

Based on the results of this investigation, we could suggest further that the motivation to perform OCB could be multilayered. That is to say, beyond the benevolent motivation, OCB may be a reaction to an ambiguous environment, where the employee is unsure about the justice in the reward system. Under such conditions, the employees may (a) diversify their work-related positive activities, and (b) invest more efforts in advertising such actions, in the hope that such diversification would increase the probability of gaining personal benefits.

This suggested mechanism may explain the strong positive correlation found between the perception of organizational politics and self-reported OCB. The close association between these two factors may indicate that in a highly political climate, in which the rules governing the allocation of organizational benefits and rewards are uncertain and perceived as unjust, there is a greater tendency to increase the scope of informal work-related behaviors beyond the formal set of requirements. Simultaneously, as indicated, those same employees attempt to 
create an impression of OCB in the hope that such tactics improve their image in the eyes of those who control their organizational benefits, including promotion within the organization. On the other hand, given a lower perception of OP, there is greater certainty about how job behavior is rewarded, and there is a lesser need to create an impression, either genuine or false, of contributing in other ways to the organization. This finding supports Ralston and Elsass's hypothesis that a high perception of OP leads to a high level of impression management efforts (Ralston \& Elsass, 1989). Our interpretation of the results suggests that employees may use OCB as a coping mechanism to overcome the threatening impact of political climate.

The hypothesized effects of the three mediating variables were clearly supported by the results. Employees perceive their work environment through a complex stream of cues from various sources. The perception of OP, as well as the perception of one's superior, rely on sources such as coworkers' gossip and information, personal experiences, and the assessment of individuals in one's surroundings. The processing of this complex data is probably also affected by personality characteristics. The consequent employee behavior reflects the way such perceptions are combined. This study proposed a mediation pattern of relations. The results demonstrate that transformational leadership and transactional leadership, respectively, mediate the relationship between OP and OCB significantly, albeit in opposite directions.

The findings concerning transactional leadership were significant only with regard to OCB-I, the interpersonal dimension of organizational citizenship behaviors. It was found that the stronger the perception of the leader as transactional, the weaker the positive relations between OP and OCB-I. As noted, the transactional leader emphasizes a system that rewards specific desirable behaviors and punishes undesirable behavior among followers. The stronger this leadership style is, the more clarity there is in the atmosphere, and the greater the confidence that behavior is monitored and rewarded systematically and predictively. Subordinates increasingly feel that they know what is expected of them, and which behaviors will be rewarded. Such clarity reduces the need among employees to expand their efforts to activities outside their defined role or to inflate the impression of OCB in a self-reported questionnaire. In that respect, the atmosphere of mistrust and uncertainty created by a political climate in the organization is mediated by the extent to which an atmosphere of clarity is induced by the transactional leader.

By way of contrast, transformational leaders operate as role models: They tend to create a group identity among their followers, and they inspire and encourage independence among that group's membership. Transformational leaders do not offer specific clarity or attempt to reduce an existing level of the political climate. Presumably, because this leadership style empowers the group members, the superior is less likely to shield them from a highly-charged political climate, where certainty about the rules of reward allocation is lacking. The stronger the superior's transformational style is, the more the employees are inclined to rely on their own resources that incorporate making greater attempts to develop an image of a high OCB performer in the hope that a wider range of positive behaviors may work in their favor.

Resilience was also found to be a significant mediator of the relationship between OP and OCB. More specifically, the association between OP and OCB becomes stronger when the level of personal resilience is higher. As hypothesized, the more resilient individual is capable of handling the stress resulting from the political climate, and acts positively and more intensely to emphasize the venue of citizenship behavior attempting to diversify the efforts that potentially create a positive impression.

In summary, the results of this study point towards an interesting and as yet unexplored facet of Organizational Citizenship Behavior. Originally, OCB was described as employees' discretionary actions beyond their formal job descriptions, which are not compensated by the organization. The pattern of relationships among this study's variables, however, indicates that when there is a lack of trust that stems from perceived unfairness and injustice in the organization's system of reward allocations, there is greater inclination among employees to enhance OCB, or to promote the impression of OCB, presumably in the hope of improving the probability of reward.

As we observed, a higher organizational political climate is associated with higher OCB. This association is strengthened under high transformational leadership, but reduced under transactional leadership, which is associated with clearer reward exchange rules. Highly resilient employees, who trust their ability to improve their situation, also tend to increase OCB when OP is higher.

\section{Conclusion}

\subsection{The Contribution of This Study}

The results of this study contribute significantly to our existing knowledge about the dynamics of organizational politics and about OCB. They offer a new perspective to our understanding of the concepts of OP and OCB. The 
findings suggest that a high level of political behavior in organizations, which, in itself, is viewed negatively by researchers, may actually encourage some very desirable employee behaviors; namely, OCB. In view of the main body of OCB literature, the findings support the relatively recent claims that there is a darker side to OCB, and that it does not necessarily stem from organizational involvement or genuine personal benevolent attitudes. It may rather reflect coping behavior in the face of uncertainty, concern and fear. If the present findings are further supported and validated by future research, the need will arise for some new discussion of both OCB and OP, revisiting the behavioral implications of both in organizational life.

\subsection{Implications for Further Research}

Validate and provide further support for the findings. Additional research is clearly needed to further explore the more specific nature of this pattern. The present model should be applied to additional diversified samples using qualitative measures such as interviews and as well as quantitative measures not limited to self-reporting questionnaires.

Impression management. A related question in the context of the present findings pertains to the distinction made in the literature between genuine OCB and the impression management of OCB. Future research should focus on this question and develop methodology capable of making this distinction. It is expected that the pattern of relations reported in this study will apply specifically to the impression management of OCB rather than to genuine OCB. Research support for this hypothesis will extend and provide further validity to the present interpretation of the finding.

Examine the extent of OCB stemming from OP. The scope of OCB motivated by OP should be studied and compared with OCB stemming from benevolent motives. Obviously, empirical research in this direction will have to rely on self-reported questionnaires as well as interviews.

Explore additional mediating variables. The present research focused on leadership and resilience as mediating variables. Future research should explore additional mediating and possibly intervening variables in this context in order to enrich our detailed understanding of the scope of relationship between OP and OCB.

Examine the sustainability of $O C B$ stemming from high $O P$. It may be assumed that OCB resulting from a high OP climate will be less sustainable and more opportunistic than OCB resulting from real good citizenship. Future longitudinal research should attempt to address this question in organizations.

We hope that the present study will instigate further investigation of these proposed directions.

\section{References}

American Psychological Association. (2014). The Road to Resiliency. Retrieved from https://studentsuccess.unc.edu/files/2015/08/The-Road-to-Resiliency.pdf

Avolio, B. J., \& Bass, B. M. (1991). The full range of leadership development. New York, NY: Bass, Avolio \& Associates.

Bacharach, S. B. (2005). Get them on your side. Avon, Mass: Platinum Press.

Bakker, A. B., \& Demerouti, E. (2014). Job demands-resources theory. In P. Y. Che \& C. L. Cooper (Eds.), Wellbeing: A complete reference guide (Vol. III, pp.37-64). New York: Wiley Blackwell. https://doi.org/10.1002/9781118539415.wbwell019

Bass, B. M. (1985). Leadership and performance beyond expectations. New York, NY: Free Press.

Bass, B. M. (2007). From transactional to transformational leadership: Learning to share the vision. In R.P. Vecchio (Ed.), Leadership: Understanding the dynamics of power and influence in organizations (2nd ed., pp. 302-317). Notre Dame, IN: University of Notre Dame Press. https://doi.org/10.2307/j.ctvpg85tk.29

Bergeron, D. M., \& Thompson, R. S. (2020). Speaking up at work: The role of perceived organizational support in explaining the relationship between perceptions of organizational politics and voice behavior. Journal of Applied Behavioral, 56, 195-215. https://doi.org/10.1177\%2F0021886319900332

Bogler, R., \& Somech, A. (2019). Psychological capital, team resources and organizational citizenship behavior. Journal of Psychology, 153(8), 784-802. https://doi.org/10.1080/00223980.2019.1614515

Bolino, M. C. (1999). Citizenship and Impression Management: Good Soldiers or Good Actors? Academy of Management Review, 24(1), 82-98. https://doi.org/10.5465/amr.1999.1580442

Bolino, M. C., Klotz, A. C., Turnley, W. H., \& Harvey, J. (2013). Exploring the dark side of organizational citizenship behavior. Journal of Organizational Behavior, 34(4), 542-559. https://doi.org/10.1002/job.1847 
Bonnano, G. A. (2004). Loss, trauma, and human resilience: Have we underestimated the human capacity to thrive after extremely aversive events? American Psychologist, 59(1), 20-28. https://doi.org/10.1037/0003-066X.59.1.20

Britt, T. W., Shen, W., Sinclair, R. R., Grossman, M. R., \& Klieger, D. M. (2016). How much do you really know about employee resilience? Industrial and Organizational Psychology: Perspectives on Science and Practice, 9(02), 378-404. https://doi.org/10.1017/iop.2015.107

Carver, C. S. (1998). Resilience and thriving: Issues, models and linkages. Journal of Social Issues, 54(2), 245-266. https://doi.org/10.1111/j.1540-4560.1998.tb01217.x

Chernyak-Hai, L., \& Rabenu, E. (2018). The new era workplace relationships: Is social exchange theory still relevant? Industrial and Organizational Psychology, 11(3), 456-481. https://doi.org/10.1017/iop.2018.5

Connor, K. M., \& Davidson, J. R. (2003). Development of a new resilience scale: The Connor-Davidson resilience scale (CD-RISC). Depression and Anxiety, 18, 76-82. https://doi.org/10.1002/da.10113

Crawford, E., LePine, J. A., \& Rich, B. L. (2010). Linking Job Demands and Resources to Employee Engagement and Burnout: A Theoretical Extension and Meta-Analytic Test. Journal of Applied Psychology, 95(5), 834-48. https://doi.org/10.1037/a0019364

Drory, A. (1993). Perceived political climate and job attitudes. Organizational Studies, 14, 59-71. https://doi.org/10.1177\%2F017084069301400105

Ferris, G. R., \& Kacmar, K. M. (1992). Perceptions of organizational politics. Journal of Management, 18, 93-116. https://doi.org/10.1177/014920639201800107

Ferris, G. R., Russ, G., \& Fandt, P. (1989). Politics in organizations. In R.A. Giacalone \& P. Rosenfeld (Eds.), Impression Management in the Organization (pp.143-170). Hillsdale, N.J.: Erlbaum.

Fikretoglu, D., \& McCreary, D. R. (2012). Psychological Resilience: A brief review of definitions, and key theoretical, conceptual and methodological issues (Technical Report 2012-012). Toronto, ON: Defense R\&D.

Gorman, C. A., Meriac, J. P., Overstreet, B. L., Apodaca, S., McIntyre, A. L., Park, P., \& Godbey, J. N. (2012). A meta-analysis of the regulatory focus nomological network: Work-related antecedents and consequences. Journal of Vocational Behavior, 80(1), 160-172. https://doi.org/10.1016/j.jvb.2011.07.005

Harris, K. J., Harris, R. B., \& Wheeler, A. R. (2009). Relationships Between Politics, Supervisor Communication, and Job Outcomes. Journal of Applied Social Psychology, 39(11), 2669-2688. https://doi.org/10.1111/j.1559-1816.2009.00543.x

Henderson, A. A., Foster, G. C., Matthews, R. A., \& Zickar, M. J. (2019). A Psychometric Assessment of OCB: Clarifying the Distinction Between OCB and CWB and Developing a Revised OCB Measure. Journal of Business and Psychology, 35, 1-16. https://doi.org/10.1007/s10869-019-09653-8

Henderson, A. A., Foster, G., Mathews, R. A., \& Zickar, M. J. (2020). A psychometric distinction between OCB and CWB and developing a revised OCB measure. Journal of Business and Psychology, 35, 697-712. https://doi.org/10.1007/s10869-019-09653-8

Hernandez, M., Eberly, M., Avolio, B. J., \& Johnson, M. D. (2011). The loci and mechanisms of leadership: Exploring a more comprehensive view of leadership theory. The Leadership Quarterly, 22(6). https://doi.org/10.1016/j.leaqua.2011.09.009

Hobfoll, S. E. (2002). Social and psychological resources and adaptation. Review of General Psychology, 6(4), 307-324. https://doi.org/10.1037/1089-2680.6.4.307

Hochwarter, W. A., Rose, C. C., \& Jordan, S. L. (2020). Perceptions of organizational politics research: Past, present and future. Journal of Management, 46, 879-907. https://doi.org/10.1177\%2F0149206319898506

Jawahar, I. M., Schreurs, B., \& Mohammed, S. J. (2018). How and when LMX quality relates to counterproductive performance: a mediated moderation model. Career Development International, 23(6/7), 557-575. https://doi.org/10.1108/CDI-05-2018-0134

Jung, D. I., \& Avolio, B. J. (1999). Effects of leadership style and followers' cultural orientation on performance in group and individual task conditions. Academy of Management Journal, 42(2), 208-218. https://psycnet.apa.org/doi/10.2307/257093

Kacmar, K. M., \& Carlson, D. S. (1997). Further validation of the perceptions of politics scale (POPS): A 
multiple sample investigation. Journal of Management, 23, 627-658.

https://doi.org/10.1177/014920639702300502

Kacmar, K. M., Bozeman, D. P., Carlson, D. S., \& Anthony, W. P. (1999). An examination of the perceptions of organizational politics model: Replication and extension. Human Relations, 52, 383-416. https://doi.org/10.1177\%2F001872679905200305

Kanat-Maimon, Y., Elimelech, M., \& Roth, G. (2020). Work motivations as antecedents and outcomes of leadership: Integrating self-determination theory and full range leadership theory. European Management Journal, 38, 555-564. https://doi.org/10.1016/j.emj.2020.01.003

Kark, R., Katz-Navon, T., \& Delegach, M. (2015). The Dual Effects of Leading for Safety: The Mediating Role of Employee Regulatory Focus. Journal of Applied Psychology 100(5), 1332-1348. https://doi.org/10.1037/a0038818

Kark, R., Van Dijk, D., \& Vashdi, D. R. (2018). Motivated or demotivated to be creative: The role of self-regulatory focus in transformational and transactional leadership processes. Applied Psychology: An International Review, 67(1), 186-224. https://doi.org/10.1111/apps.12122

Kipnis, D., Schmidt, S. M., \& Wilkinson, I. (1980). Intraorganizational influence tactics: Explorations in getting one's way. Journal of Applied Psychology, 65(4), 440-452. https://doi.org/10.1037/0021-9010.65.4.440

Ladebo, O. J. (2006) Perceptions of Organizational Politics: Examination of a Situational Antecedent and Consequences among Nigeria's Extension Personnel. Applied Psychology: An International Review, 55(2), 255-281. https://doi.org/10.1111/j.1464-0597.2006.00230.x

Lau, P. L., Wilkins-Yel, K. G., \& Wong, Y. J. (2020). Examining the indirect effects of self- concept on work readiness through resilience and career calling. Journal of Career Development, 47, 551-564. https://doi.org/10.1177\%2F0894845319847288

Madrid, H. P., Diaz, M. T., Leka, S., Leiva, P. I., \& Barros, E. (2018). A finer grained approach to psychological capital and work performance. Journal of Business and Psychology, 33(4), 461-477. https://doi.org/10.1007/s10869-017-9503-z

Masten, A. S. (2001). Ordinary magic: Resilience processes in development. American Psychologist, 56(3), 227-238. https://doi.org/10.1037/0003-066X.56.3.227

Meredith, L. S., Sherbourne, C. D., Gaillot, S. J., Hansell, L., Ritschard, H. V., Parker, A. M., \& Wrenn, G. (2011). Promoting Psychological Resilience in the U.S. Military. Santa Monica, CA: RAND Corporation.

Newman, R. (2005). APA's Resilience Initiative. Professional Psychology: Research and Practice, 36(3), 227-229. https://doi.org/10.1037/0735-7028.36.3.227

Oren, L., Tziner, A., Nahshon, Y., \& Sharoni, G. (2013). Relations between OCBs, organizational justice, work motivation and self-efficacy. Amfiteatru Economic Journal, 15(34), 505-517.

Organ, D. W. (1988). Organizational Citizenship behavior: The good soldier syndrome. Lexington, MA: Lexington Books.

Oshio, A., Taku, K., Hirano, M., \& Saeed, G. (2018). Resilience and Big Five personality traits: A meta-analysis. Personality and Individual Differences, 127, 54-60. https://doi.org/10.1016/j.paid.2018.01.048

Parker, M. R., Subrahmanian, T., \& Hussain, I. (in press). Creating organizational citizens: How and when supervisor versus peers led role interventions change Organizational Citizenship Behavior. Journal of Applied Psychology.

Perilla-Toro, L. E., \& Gómez-Ortiz, V. (2017). Relación del estilo de liderazgo transformacional con la salud y el bienestar del empleado: El rol mediador de la confianza en el líder [Relationship of transformational leadership style with employee health and well-being: The mediating role of trust in the leader]. Journal of Work and Organizational Psychology, 33(2), 95-108. https://doi.org/10.1016/j.rpto.2017.02.005

Podsakoff, N. P., Whiting, S. W., Podsakoff, P. M., \& Blume, B. D. (2009). Individual-and organizational-level consequences of organizational citizenship behaviors: A meta-analysis. Journal of Applied Psychology, 94(1), 122-141. https://psycnet.apa.org/doi/10.1037/a0013079

Podsakoff, P. M., Mackenzie, S. B., Lee, J. Y., \& Podsakoff, N. P. (2003). Common method biases in behavioral research: A critical review of the literature and recommended remedies. Journal of Applied Psychology, 88(5), 879-903. https://doi.org/10.1037/0021-9010.88.5.879 
Porpora, D. V. (1989). Four concepts of social structure. Journal for the Theory of Social Behavior, 19(2), 195-211. https://doi.org/10.1111/j.1468-5914.1989.tb00144.x

Ralston, D. A., \& Elsass, P. M. (1989). Ingratiation and impression management in the organization. In R. A. Giacalone \& P. Rosenfeld (Eds.), Impression Management in the Organization (pp. 235-249). Hillsdale, NJ: Lawrence Erlbaum associates.

Shkoler, O., \& Tziner, A. (2020). Leadership styles as predictor of work attitudes: A moderated-mediation link. Amfiteatru Economic, 22, 164-187. https://doi.org/10.24818/EA/2020/53/164

Spitzmuller, M., Van Dyne, L., \& Ilies, R. (2008). Organizational citizenship behavior. A critical review and extension of its nomological network. In C. Cooper \& J. Barling (Eds.), Handbook of Organizational Behavior. Sage Publishing.

Tehseen, S., Ramayah, T., \& Sajilan, S. (2017). Testing and controlling for common method variance: a review of available methods. Journal of Management Sciences, 4(2), 142-168. https://doi.org10.20547/jms.2014.1704202

Turnipseed, D. L. (2018). Emotional intelligence and OCB: The moderating role of work locus of control. The Journal of Social Psychology, 158(3), 322-336. https://doi.org/10.1080/00224545.2017.1346582

Tziner, A., \& Sharoni, G. (2014). Organizational citizenship behavior, organizational justice, job stress, and work-family conflict: Examination of their interrelationships with respondents from a non-Western culture. Revista de Psicología del Trabajo y de las Organizaciones, 30(1), 35-42. https://doi.org/10.5093/tr2014a5

Tziner, A., Shkoler, O., \& Fein, E. C. (2020). Examining the effects of cultural value orientations, emotional intelligence, and motivational orientations: How does LMX mediation and gender-based moderation make a difference? Frontiers in Psychology, 11, 2717. https://doi.org/10.3389/fpsyg.2020.502903

Vigoda-Gadot, E. (2006). Compulsory Citizenship Behavior: Theorizing Some Dark Sides of the Good Soldier Syndrome in Organizations. Journal for the Theory of Social Behavior, 36(1), 77-93. https://doi.org/10.1111/j.1468-5914.2006.00297.x

Vigoda-Gadot, E. (2003). Developments in organizational politics: How political dynamics affect employee performance in modern work sites. Cheltenham, UK: Edward Elgar.

Vigoda-Gadot, E., \& Drory, A. (Eds.). (2016). Handbook of organizational politics: Looking back and to the future (2nd ed.). Cheltenham, UK: Edward Elgar. https://doi.org/10.4337/9781784713492

Vigoda-Gadot, E., \& Kapun, D. (2005). Perceptions of politics and perceived performance in public and private organizations: a test of one model across two sectors. Policy \& Politics, 33(2), 251-276. https://doi.org/10.1332/0305573053870185

Vigoda-Gadot, E., \& Talmud, I. (2010). Organizational Politics and Job Outcomes: The Moderating Effect of Trust and Social Support. Journal of Applied Social Psychology, 40(11), 2829-2861. https://doi.org/10.1111/j.1559-1816.2010.00683.x

Walpita, Y. N., \& Arambepola, C. (2020). High resilience leads to better work performance in nurses: Evidence from South-Asia. Journal of Nursing, 28, 342-350. https://doi.org/10.1111/jonm.12930

Williams, L. J., \& Anderson, S. E. (1991). Job satisfaction and organizational commitment as predictors of organizational citizenship and in-role behaviors. Journal of Management, 17, 601-617. https://doi.org/10.1177\%2F014920639101700305

Xenikou, A. (2017). Transformational Leadership, Transactional Contingent Reward, and Organizational Identification: The Mediating Effect of Perceived Innovation and Goal Culture Orientations. Frontiers in Psychology, 8, Article 1754. https://doi.org/10.3389/fpsyg.2017.01754

Yaffe, T., \& Kark, R. (2011). Leading by example: The case of leader OCB. Journal of Applied Psychology, 96(4), 806-826. https://doi.org/10.1037/a0022464

\section{Copyrights}

Copyright for this article is retained by the author(s), with first publication rights granted to the journal.

This is an open-access article distributed under the terms and conditions of the Creative Commons Attribution license (http://creativecommons.org/licenses/by/4.0/). 